\title{
MODELING THE EFFECTS OF THE GLOBAL FINANCIAL CRISIS ON THE MALAYSIAN MARKET
}

\author{
Amir Angabini and Shaista Wasiuzzaman
}

\begin{abstract}
Stock market volatility is important in determining the cost of capital and to assess investment and leverage decisions since volatility is synonymous with risk. Risk-averse investors could be affected negatively due to substantial changes in volatility of the financial markets. We focus on the global crisis of 2007/2008 and its impact on the Malaysian financial market. We use GARCH models to model the volatility in order to determine the effect of the crisis on the KLCI. In order to be able to model the volatility, we first test the efficiency of the market using ARIMA models. We found that because of the financial crisis there was an increase in the impact of news about volatility from the previous periods but only a slight drop in the persistency of the conditional variance.
\end{abstract}

Index Terms-Financial market, volatility forecasting, global financial crisis

\section{INTRODUCTION}

The end of 2007 and the beginning of 2008 witnessed the onset of global financial crisis which caused a havoc to the financial markets around the world. What started as a liquidity shortfall in the United States banking system, soon spread around the globe. Global security markets suffered huge losses and Malaysia was no exception. Between 14 January 2008 and 12 September 2008, a drop of around 670 points (which comes to about $45 \%$ of its value) was experienced by the KLCI, which was the main index and market indicator in Malaysia. Such a huge drop was last experienced during Asian financial crisis of 1997. However, when things started settling down, the general consensus was that the Asean countries were not very severely affected by the global financial crisis because of the precautions taken by these countries in securing their financial market after the Asian financial crisis.

The question does arise then as to the size of the impact of the 2008 global financial crisis on the stock market volatility. The main objective of this study is thus to investigate the volatility of the Bursa Malaysia with regards to the recent financial crisis of 2007/2008, after the Asian financial crisis 1997.

\section{LITERATURE REVIEW}

Changes in volatility are a huge concern to investors and regulators alike. Several studies have been conducted and methodologies constructed in the attempt to model these

Amir Angabini, Faculty of Mangement, Multimedia University, Cyberjaya, Malaysia, amir_2005641@yahoo.com

Shaista Wasiuzzaman, Faculty of Management, Multimedia University, Cyberjaya, Malaysia, shaista@mmu.edu.my changes and the ARCH/GARCH family of models has been shown to be the best so far.

$\mathrm{ARCH}$ effects are documented in the finance literature by Hsieh [1] for five different US dollar rates, Akgiray [2] for index returns, Schwert [3] for future markets, and Engle and Mustafa [4] for individual stock returns. Diebold [5], Baillie and Bollerslev [6] and Drost and Nijman [7] found that ARCH effects, which are highly significant with daily and weekly data, weaken as the frequency of the data decreases. Diebold and Nerlove [8] try to explain the existence of $\mathrm{ARCH}$ effects in the high frequency data due to the amount of information or the quality of the information reaching the markets in clusters or the time between information arrival and the processing of information by market participants.

Brailsford and Faff [9] argue that volatility forecasting is very difficult and though in their study $\mathrm{ARCH}$ models and simple regression provided superior forecasting ability, the models were 'sensitive to the error statistic used to assess the accuracy of the forecasts'. Brooks et al. [10] support the applicability of the ARCH-GARCH models to SouthAfrican stock data. However, Barucci and Reno [11] find that GARCH models have better forecasting properties when Fourier analysis is used to calculate the diffusion process volatility, instead of the cumulative squared intraday returns.

Rijo [12] also find that the $\operatorname{GARCH}(1,1)$ model gives the best fit for the National Stock Exchange (NSE) of India Radha and Thenmozhi [13] forecast short term interest rate using ARMA, ARMA-GARCH and ARMA-EGARCH on the Indian market. Their results show that GARCH based models are more appropriate for forecasting than the other models. Padhi [14] uses the ARCH, GARCH and ARCH-inmean models to explain the stock market volatility of the Indian market at the individual script level and at the aggregate indices level. The analysis reveals the same trend of volatility in the case of aggregate indices and five different sectors and the $\operatorname{GARCH}(1,1)$ model is persistent for all the five aggregate indices and individual companies. The study on the effect of the global financial crisis on stock return volatility in India by Mishra [15] on the S\&P CNX Nifty using GARCH models concludes the persistence of stock return volatility and its asymmetric effect.

Ederington and Guan [16] compare the forecasting ability of various volatility forecasting models and find that the $\operatorname{GARCH}(1,1)$ model 'generally yields better forecasts than the historical standard deviation and exponentially weighted moving average models..' but some reservations are still there in terms of the forecasting accuracy. Awartani and Corradi [17] find that when allowing for asymmetries, the 
$\operatorname{GARCH}(1,1)$ model is beaten by the asymmetric GARCH models, but when not allowing for asymmetries it was the best model compared to other GARCH models.

Magnus and Fosu [18] reject the random walk hypothesis for the Ghana Stock Exchange and support the superiority of the $\operatorname{GARCH}(1,1)$ model compared to other models 'under the assumption that the innovations follow a normal distribution.' Shamiri and Abu Hassan [19] model and forecast the volatility of the Malaysian and the Singaporean stock indices using Asymmetric GARCH. They estimate the three GARCH $(1,1)$ models $(\mathrm{GARCH}, \mathrm{EGARCH}$ and GJRGARCH) using daily price data. They find that the AR(1)GJR model provides the best out-of- sample forecast for the Malaysian stock market, while AR(1)-EGARCH provide a better estimation for the Singaporean stock market which implies that Malaysian stock market has asymmetric effects. Haniff and Pok [20] compare the four non-period GARCH models and find that the EGARCH produced consistently superior results compared to the other GARCH models.

\section{Methodology And Data Analysis}

The Asian financial crisis in 1997 caused a huge collapse of the stock markets in the South East Asian region. However, from January 2000 onwards, stock prices had resumed their increasing trend until the eve of the outbreak of the global financial crisis. Malaysia had a good recovery by the middle of 1999 . There is no specific date of full economic recovery, but by the middle of 2000 , it had almost recovered. Guidi [21] showed that there was a downward trend in the patterns of prices of Asian stock markets towards the end of 2007 with signals of recovery from the late 2008 .

Thus, in order to capture the impact of the crisis, two different periods are used to see the effect and both periods are selected after the recovery of Asian financial, which was in the middle of year 2000, to make sure there is no effect of the 1997 Asian financial crisis in our analysis. This study uses secondary data collected from DataStream, covering a period of six and a half years after the East Asian financial crisis of 1997 and before the global crisis of 2008. We analyze data from 1st June 2000 until the end of 2007 and then a period of 10 years from $1^{\text {st }}$ of June 2000 until the $16^{\text {th }}$ of March 2010 which includes the crisis which happened at the end of year 2007 and beginning of year 2008. In the first analysis the crisis is excluded but it is included in the second analysis, so if there is any impact of the crisis, a significant change in the models can be detected. We use the daily closing price of the Kuala Lumpur Composite Index (KLCI) to analyze the volatility

The prices are used to get the daily returns of the KLCI as below:

$$
\mathrm{R}_{\mathrm{t}}=\log \left(\mathrm{P}_{\mathrm{t}} / \mathrm{P}_{\mathrm{t}-1}\right)
$$

Where $R_{t}$ represents the daily returns of the KLCI $\mathrm{P}_{\mathrm{t}}$ represents the daily prices of the KLCI

We run the unit root test to detect stationarity of this series for both periods and the results are presented in Table 1 below:
TABLE I. UNIT ROOT TEST

\begin{tabular}{|c|c|c|}
\hline Period & t-Statistic & P-value \\
\hline June 2000 to end of 2007 & -36.92449 & $0.0000^{*}$ \\
\hline June 2000 to March 2010 & -43.30531 & $0.0000^{*}$ \\
\hline
\end{tabular}

The null hypothesis that both the series are non-stationary is rejected with a low $p$ value of 0.000 and we conclude that both the series are stationary.

Next, we estimate and select the best ARMA model that fits the return of the series. We select our model based on the p-values, residual of Q-statistic $\mathrm{p}$ values and AIC values. Among the models, some are rejected due to the stationary condition since the sum of the absolute coefficients is greater than 1 and some are rejected due to magnitude of their p-values. Then, the ARMA models with residuals that are statistically different from zero can be rejected as it means that the residuals are not just white noise. All our models have residuals which are white noise.

The good models which satisfy all of the conditions are as in Table 2 below:

TABLE II. GOOD ARMA MODELS

\begin{tabular}{|c|c|c|}
\hline Model & \multicolumn{2}{|c|}{ AIC } \\
\hline & 2000 to 2007 & 2000 to 2010 \\
\hline ARMA (1,0) & -6.704296 & -6.578003 \\
\hline ARMA (0,1) & -6.704299 & -6.577677 \\
\hline ARMA (1, 1) & -6.704005 & -6.577360 \\
\hline ARMA (2,0) & -6.703790 & -6.577339 \\
\hline ARMA (0, 2) & -6.703325 & -6.576896 \\
\hline ARMA (3,0) & -6.705046 & -6.578815 \\
\hline ARMA (0,3) & -6.705113 & -6.578370 \\
\hline ARMA (4,0) & -6.707036 & -6.579161 \\
\hline ARMA (0,4) & -6.704510 & -6.577587 \\
\hline
\end{tabular}

According to Akaike's information criterion, ARMA $(4,0)$ is chosen to be the best model among all for both periods of study as it has the lowest AIC.

It is worth mentioning here that the random walk is a nonstationary stochastic process and implies that the best prediction of the price of a stock tomorrow is equal to its price today plus a purely random (stochastic) shock (error term). If this were in fact the case, forecasting assets prices would be an unsuccessful exercise [22]. So if the time series does not follow a random walk, it means they are somehow correlated and a model for forecasting can be employed and at the same time reject the weak form market efficiency since we can find a pattern in time series for prediction.

The random walk can be described by a particular ARIMA model which is ARIMA $(0,1,0)$. Here, the first zero refers to the Autoregressive process and second zero to the moving average process which indicates some extent of dependency and correlation in the series, which is in conflict with random walk properties. One refers to the degree of differencing. If we model the series and do not find the ARIMA model mentioned above, we can assume that model is not a random walk and as a result reject the weak-from market efficiency.

We find that the model does not follow the ARIMA $(0,1$, $0)$ as it was detected earlier that the data is stationary and no differencing is required. The market did not follow the random walk and so was not weak-efficient form for both periods. 
Next, we perform the ARCH LM test to see if there is any ARCH effect in the residuals. Table 3 below presents the results of this test.

TABLE III. ARCH LM TEST

\begin{tabular}{|c|c|c|}
\hline & $\mathbf{2 0 0 0}$ to 2007 & $\mathbf{2 0 0 0}$ to 2010 \\
\hline F-statistic & 70.91180 & 67.25315 \\
& $(0.0000)$ & $(0.0000)$ \\
\hline Obs*R-squared & 68.51745 & 65.57384 \\
& $(0.0000)$ & $(0.0000)$ \\
\hline
\end{tabular}

The LM test for both periods shows a significant presence of $\mathrm{ARCH}$ effect with a value of 68.5174 (for the period of 2000 to 2007) and 65.57384 (for the period of 2000 to 2010) and low $\mathrm{P}$ value of 0.0000 for both periods. So, we reject the null hypothesis of no ARCH effect and detect a strong presence of ARCH effect.

Since there is an ARCH effect in the residuals, we need to model this too using the ARCH/GARCH models. To test the adequacy of the GARCH models, it is necessary to examine the standardized residuals, $\varepsilon_{t} / \sigma_{t}$, such that $\sigma_{t}$ is the conditional standard deviation as calculated by the GARCH model and $\varepsilon_{t}$ are the residuals of the conditional mean equation. If the GARCH model is well specified, the standardized residuals will be independent and identically distributed, for which the Q-statistics should be more than 0.05. Table 4(a) and 4(b) below present the estimation for the different $\operatorname{GARCH}(\mathrm{p}, \mathrm{q})$ models for both periods. We assume that the innovation term follows a normal distribution as was done by Magnus and Fosu [18]. Here Alpha refers to the value of previous square error term and Beta refers to the value of previous variances.

TABLE IVA. DifFERENT GARCh Models For The PERIOD 2000 To 2007

\begin{tabular}{|c|c|c|c|c|c|}
\hline $\begin{array}{c}\text { GARC } \\
\text { Hodel }\end{array}$ & Coefficient & $P$ values & $\begin{array}{c}\begin{array}{c}\text { Standar } \\
\text { dized } \\
\text { residual }\end{array} \\
\text { s } \\
Q- \\
\text { statistic } \\
\text { s } \\
\text { p-values }\end{array}$ & $\begin{array}{c}\begin{array}{c}\text { Standar } \\
\text { dized } \\
\text { residual } \\
\text { s }\end{array} \\
\text { squared } \\
\text { Q- } \\
\text { statistics } \\
\text { p-values }\end{array}$ & AIC \\
\hline$(1,0)$ & $\begin{array}{l}\text { Alpha1: } \\
0.3034\end{array}$ & 0.0000 & 0.673 & 0.000 & -6.7980 \\
\hline$(1,1)$ & $\begin{array}{l}\text { Alpha1: } \\
0.0906 \\
\text { Beta1: } \\
0.8969 \\
\end{array}$ & $\begin{array}{c}\text { Alpha1: } 0 \\
\text { Beta1: } 0\end{array}$ & 0.933 & 0.834 & -6.9419 \\
\hline$(2,1)$ & $\begin{array}{l}\text { Alpha1: } \\
0.1441 \\
\text { Alpha2: - } \\
0.08449 \\
\text { Beta1: } \\
0.931876\end{array}$ & $\begin{array}{l}\text { Alpha1: } 0 \\
\text { Alpha2: } 0 \\
\text { Beta1: } 0\end{array}$ & 0.956 & 0.866 & -6.9445 \\
\hline$(2,2)$ & $\begin{array}{c}\text { Alpha1: } \\
0.0796 \\
\text { Alpha2: } \\
0.0942 \\
\text { Beta1: - } \\
0.0501 \\
\text { Beta2: } \\
0.8527 \\
\end{array}$ & $\begin{array}{c}\text { Alpha1: } \\
0 \\
\text { Alpha2: } 0 \\
\text { Beta1:0.02 } \\
\text { Beta2:0 }\end{array}$ & 0.923 & 0.859 & -6.9414 \\
\hline
\end{tabular}

TABLE IVB. DifFERENT GARCH MODELS FOR THE PERIOD 2000 To 2010

\begin{tabular}{|c|c|c|c|c|c|}
\hline $\begin{array}{c}\text { GARCH } \\
\text { model }\end{array}$ & Coefficient & P values & $\begin{array}{c}\text { Standar } \\
\text { dized } \\
\text { residual } \\
\text { s } \\
\text { Q- } \\
\text { statistics } \\
\text { p-values } \\
\text { (lag 500) }\end{array}$ & $\begin{array}{c}\text { Standar } \\
\text { dized } \\
\text { residual } \\
\text { s } \\
\text { squared } \\
\text { Q- } \\
\text { statistics } \\
\text { p-values }\end{array}$ & AIC \\
& & & & & \\
& & & & & \\
\hline$(1,0)$ & Alpha1: & Alpha1: & 0.005 & 0.000 & -6.6507 \\
& 0.350438 & 0.0 & & & \\
\hline$(1,1)$ & Alpha1: & Alpha:0. & 0.835 & 0.784 & -6.8380 \\
& 0.112945 & 0 & & & \\
& Beta1: & Beta1: & & & \\
& 0.877529 & 0.0 & & & -6.8374 \\
\hline$(2,1)$ & Alpha1: & Alpha1: & 0.826 & 0.755 & \\
& 0.103713 & 0.0 & & & \\
& Alpha2: & Alpha2: & & & \\
& 0.017279 & 0.28 & & & \\
& Beta1: & Beta1: & & & \\
& 0.868238 & 0.0 & & & \\
& & & & & \\
\hline
\end{tabular}

Among all these models, the $\operatorname{GARCH}(1,1)$ is the best model for both periods under study as it satisfies all conditions. The GARCH $(2,1)$ has higher AIC value but a negative coefficient which is not allowed in ARCH/GARCH models. As seen in previous studies, the GARCH $(1,1)$ is the successful model and we observe this here as well.

Finally, we again compute the LM statistic test after the incorporation of the GARCH into the model to check whether there is any GARCH effect left in the model. Table 5 below shows the LM statistic.

TABLE V. ARCh LM Test After GARCh Estimation

\begin{tabular}{|c|c|c|}
\hline & $\mathbf{2 0 0 0}$ to 2007 & $\mathbf{2 0 0 0}$ to 2010 \\
\hline F-statistic & 2.746304 & 0.160840 \\
& $(0.097639)$ & $(0.688418)$ \\
\hline Obs*R-squared & 2.745265 & 0.160956 \\
& $(0.097543)$ & $(0.688278)$ \\
\hline
\end{tabular}

The results of the LM test does not show any significant presence of ARCH effects, with an F-statistic value of 2.7452 and high p-value of 0.0975 , for the period of 2000 to 2007 and an F-statistic value of 0.160956 and a high p-value of 0.688278 for the period of 2000 to 2010 . So, we accept the null hypothesis of no ARCH effect and do not detect presence of $\mathrm{ARCH}$ effect anymore.

Finally, we find that the AR $(4) / \operatorname{GARCH}(1,1)$ to be the best model to capture the volatility of the market. The table 6 below presents the coefficients and statistical significance of the final model.

TABLE VI. FinAL MODEL FOR THE PERIODS OF 2000 TO 2007 AND 2000 TO 2010

\begin{tabular}{|c|c|c|}
\hline ARMA & 2000 to 2007 & 2000 to 2010 \\
\hline AR(1) & 0.178277 & 0.168785 \\
& $(0.0000)$ & $(0.0000)$ \\
\hline AR(2) & -0.004701 & 0.002496 \\
& $(0.8407)$ & $(0.9002)$ \\
\hline AR(3) & 0.051108 & 0.043695 \\
& $(0.0390)$ & $(0.0285)$ \\
\hline
\end{tabular}




\begin{tabular}{|l|c|c|}
\hline AR(4) & -0.034397 & -0.023214 \\
& $(0.1307)$ & $(0.2642)$ \\
\hline
\end{tabular}

\begin{tabular}{|c|c|c|}
\hline GARCH & 2000 to 2007 & 2000 to 2010 \\
\hline Alpha(1) & $0.090685(0.0000)$ & 0.112945 \\
& & $(0.0000)$ \\
\hline Beta(1) & $0.896916(0.0000)$ & 0.877529 \\
& & $(0.0000)$ \\
\hline
\end{tabular}

For the period of 2000 to 2007, the conditional variance has the rate of change of 0.090 and the large value of 0.89 of beta causes $\sigma_{t}^{2}$ to be highly correlated with $\sigma_{t-1}^{2}$ and gives the conditional variance process a relatively long-term persistence. For the period of 2000 to 2010, the conditional variance has the rate of change of 0.1106 and the large value of 0.87 of beta causes $\sigma_{t}^{2}$ to be highly correlated with $\sigma_{t-1}^{2}$ and again gives the conditional variance process a relatively long-term persistence.

The following Table 7 shows the conditional variance for each period, the difference and percentage change in value of the coefficients between the two time periods.

TABLE VII. DIFFERENCE BETWEEN THE GARCH MODELS

\begin{tabular}{|c|c|c|c|c|}
\hline Period & $\begin{array}{c}\mathbf{2 0 0 0} \text { to } \\
\mathbf{2 0 0 7}\end{array}$ & $\begin{array}{c}\mathbf{2 0 0 0} \text { to } \\
\mathbf{2 0 1 0}\end{array}$ & Difference & \% \\
\hline$\alpha_{1}$ & $\begin{array}{c}0.090685 \\
(0.0000)\end{array}$ & $\begin{array}{c}0.112945 \\
(0.0000)\end{array}$ & 0.02226 & $24.5465 \%$ \\
& $\begin{array}{c}0.896916 \\
\beta_{1}\end{array}$ & $\begin{array}{c}0.877529 \\
(0.0000)\end{array}$ & 0.019387 & $-2.1615 \%$ \\
\hline
\end{tabular}

The value of the beta, which indicates the correlation between $\sigma_{t}^{2}$ and $\sigma_{t-1}^{2}$, shows that the conditional variance has decreased by $2.16 \%$, which implies that the persistency in conditional variance has decreased by $2.16 \%$. On the other hand, the rate of change of conditional variance has increased by $24.5 \%$. Thus, we can say that the volatility has increased by $24.5 \%$ and at the same time the persistency in volatility has just decreased by $2.16 \%$ during the crisis period.

Since the summation of coefficients is high, the response function to shocks is likely to die slowly. In other words, if there is a new shock it will have implication on returns for a longer period. In such markets old information is more important than recent information and that the information decays very slowly.

\section{CONCLUSION}

In this study, volatility clustering effect and impact of the $2007 / 2008$ crisis on the volatility of the market was observed. The KLCI was used as the main market indicator and its returns were log transformed for each period. The data was found to be stationary, using the unit root test. Among the ARMA models examined, the ARMA $(4,0)$ or AR (4) model was selected as the best model to fit the return series according to the AIC criteria. The ARCH LM test indicated the presence of high $\mathrm{ARCH}$ effect in the residuals. So, different GARCH models were examined and the $\operatorname{GARCH}(1,1)$ model was found to be the best model among all according to the AIC criteria. This was in accordance with our expectations. Rechecking using the ARCH LM test showed no significant presence of GARCH effect.
Standardized residuals and Standardized residuals squared were also examined and found to be white noise. As a result, the $\operatorname{AR}(4) / G A R C H(1,1)$ was found to be the best model for our analysis during both the periods studied.

Also, for both periods, the prices were not found to follow the random walk. According to the results, the ARIMA (4, $0,0)$ is chosen to be the best. The random walk is best described by the ARIMA $(1,0,0)$ model. Since the data is already stationary and mean reverting it requires no differencing. Thus, there is dependency in the data structure and we conclude that for the period of 1 June 2000 until the end of 2007 and 1 June 2000 until 16 March 2010, the KLCI was not in an efficient form.

There was evidence of volatility clustering effect for both the periods under consideration as expected for stock markets. The GARCH $(1,1)$ was found to be the best model which is in line with previous research results. The two models indicated a high persistence of high or low volatility where the coefficient of $\sigma_{t-1}^{2}$ was high for both. It shows that the conditional standard deviation process has a relatively long term persistency.

The effect of the crisis can be observed by comparing the two models. The value of beta, which indicates the correlation between $\sigma_{t}^{2}$ and $\sigma_{t-1}^{2}$, gives the conditional variance a relatively long-term persistence, which has decreased by 0.0216 and this implies that the persistency in conditional variance has decreased by $2.16 \%$. On the other hand, the rate of change of conditional variance has increased by $24.5 \%$. Thus, we can say that the volatility has increased by $24.5 \%$ and at the same time the persistency in volatility has just decreased by $2.16 \%$ during the crisis period.

The results also show that for these types of markets, old information is more important than new information and the decay in information is very slow and that new shocks will have more long term implications.

\section{REFERENCES}

[1] D. A. Hsieh, "Tests of rational expectations and no risk premium in forward exchange markets," Journal of International Economics, 1984, vol. 24 , pp. 129-145.

[2] V. Agkgiray, "Conditional heteroscedasticity in time series of stock returns," Journal of Business, 1989, vol. 62, pp. 55-80.

[3] G. W. Schwert, "Stock Volatility and the Crash of '87," Review of Financial Studies, 1990, vol. 3(1), pp. 77-102.

[4] R. Engle and C. Mustafa, "Implied ARCH models from options prices," Journal of Econometrics, 1992, vol. 52, pp. 380-411.

[5] F. X. Diebold and M. Nerlove, "The Dynamics of Exchange Rate Volatility: A Multivariate Latent Factor Arch Model," Journal of Applied Econometrics, 1989, vol. 4(1), pp. 1-21.

[6] R. T. Baillie and T. Bollerslev, "The message in daily exchange rates: a conditional variance tale," Journal of Business and Economic Statistics, 1989, vol. 7, pp. 297-305.

[7] F. C. Drost and T. E. Nijman, "Temporal Aggregation of GARCH Processes," Econometrica,1993, vol. 61(4), pp. 909-927.

[8] F. X. Diebold, Empirical modeling of exchange rate dynamics, Springer Verlag, New York, 1988.

[9] T .J. Brailsford and R. W. Faff, "An evaluation of volatility forecasting techniques," Journal of Banking \& Finance, 1996, vol. 20(3), pp. 419-438.

[10] R. D. Brooks, S. Davidson and R. W. Faff, "An examination of the effects of major political change on stock market volatility: the South African experience," Journal of International Financial Markets, Institutions and Money, 1997, vol. 7(3), pp. 255-275. 
[11] E. Barucci and R. Reno, "On measuring volatility and the GARCH forecasting performance," Journal of International Financial Markets, Institutions and Money, 2001, vol. 12, pp 183 - 200.

[12] M. J. Rijo, "Presence of Conditional Heteroscesticity in Stock Returns," Unpublished, 2004.

[13] S. Radha and M. Thenmozhi,(2006), "Forecasting Short Term Interest Rates Using ARMA, ARMA-GARCH and ARMA-EGARCH Models," Indian Institute of Capital Markets 9th Capital Markets Conference Paper, 2006.

[14] P. Padhi, "Stock Market Volatility in India: A Case of Select Scripts," Unpublshed, 2006.

[15] P. K. Mishra, "Global Financial Crisis and Stock Return Volatility in India", 2009, unpublished.

[16] L. H. Erdington and W. Guan, "Forecasting volatility," The Journal of Futures Markets, vol. 2005, 25(5), pp. 465-490.

[17] B. M. A. Awartani and V. Corradi, "Predicting the volatility of the S\&P-500 stock index via GARCH models: the role of asymmetries," International Journal of Forecasting, 2005, vol. 21, pp $167-183$.
[18] F. J. Magnus and O. E. Fosu, "Modelling and Forecasting Volatility of Returns on the Ghana Stock Exchange Using Garch Models," American Journal of Applied Sciences, 2006, vol. 3(10), pp. 2042 2048.

[19] A. Shamiri and M. S. N. Abu Hassan. "Modeling and Forecasting Volatility of the Malaysian and the Singaporean stock indices using Asymmetric GARCH models and Non-normal Densities,", Journal of Malaysian Mathematical Sciences, 2007,vol. 1, pp 83-102.

[20] M. N. Haniff and W. C. Pok, "Intraday volatility and periodicity in the Malaysian stock returns," Research in International Business and Finance, 2010, vol. 24, pp. $329-343$.

[21] F. Guidi. (2010, January). Modeling and forecasting volatility of East Asian Newly Industrialized Countries and Japan stock markets with non-linear models. Munich Personal RePec Archive (MRPA) No. 19851. Available: http://ideas.repec.org/p/pra/mprapa/19851.html.

[22] D. N. Gujarati, Basic Econometrics, $3^{\text {rd }}$ Ed. Chicago: Irwin Professional Publication, 2002. 